\title{
SISTEM PAKAR FUZZY UNTUK MANAJEMEN DAUR HIDUP PRODUK
}

(Fuzzy Expert System for Product Life Cycle Management)

\author{
GYSBER JAN TAMAELA \\ Jurusan Matematika FMIPA UNPATTI \\ Jl. Ir. M. Putuhena, Kampus Unpatti, Poka-Ambon \\ E Mail: gjtamaela@yahoo.com
}

\begin{abstract}
Every product has its certain life cycle, whether, for example, it preserve in the market or have to be withdrawed from the market. Some criterias are important to determine those decisions. But they are not in numerical form but categorial one. Fuzzy logic is a tool to transform those categorial form to numerics using membership function. This research was trying to helps management as an expert system to make a decision based on computer software.
\end{abstract}

Keywords: Fuzzy expert system, Product life cycle management

\section{PENDAHULUAN}

Dalam Ensiklopedia Wikipedia, Daur Hidup Produk (Product Life Cycle) adalah "Keberhasilan sebuah produk dalam memasuki fase-fasenya”. Sementara Manajemen Daur Hidup Produk (Product Life Cycle Management) adalah "Keberhasilan strategi yang diterapkan oleh pihak manajemen sehingga sebuah produk dapat melalui fase-fase daur hidupnya dengan baik”. Pendekatan daur hidup produk menggambarkan corak perubahan dari evolusi pasar. Daur hidup berarti periode dari saat sebuah produk diluncurkan sampai kepada saat penarikan produk tersebut dari pasar dan hal ini terbagi dalam beberapa fase. Meskipun daur hidup bervariasi menurut produk dan basis sektor, secara umum biasanya terdapat 4 fase dalam periode daur hidup.

Fase pertama adalah Fase Masuk. Fase Masuk (Entrance) adalah periode dimana sebuah produk diperkenalkan ke pasar dan usaha-usaha yang dilakukan agar diterima oleh pasar. Fase berikutnya adalah Fase Pengembangan (Development) dimana fase ini adalah fase terbaik pada saat produk tersebut mencapai tingkat keuntungan (profit) maksimum dan telah melalui priode cemerlang. Pada fase yang ketiga yaitu Fase Kematangan (Maturity), masalah mulai datang secara gradual dan tingkat penjualan turun dibandingkan pada saat awal. Walaupun demikian, perusahaan tetap berusaha untuk meningkatkan penjualan dengan melakukan beberapa aktifitas dalam pemasaran. Secara umum dapat dikatakan inovasi, performansi, dan kompetisi sangat tergantung dari tingkat kedewasaan pasar. Fase terakhir yaitu Fase Kepuasan (Satisfaction) adalah fase dimana perusahaan akan secara lambat laun menarik produk tersebut dari pasar.

Selama periode kematangan, beberapa perubahan signifikan dibuat seturut dengan perilaku produk pada pasar. Karena peningkatan keuntungan adalah tujuan utama dari perusahaan, maka manajemen daur hidup produk menjadi sangat penting. Dalam daur hidup produk konvensional, perkenalan sebuah produk ke pasar adalah seperti titik $\boldsymbol{A}$ yang tergambar dalam Gambar 1. Pada saat mencapai titik ini dalam periode kematangan, perusahaan harus memilih salah satu dari beberapa alternatif: produk baru, pasar baru, atau menarik produk dari pasar agar tidak memasuki fase keempat, yang berarti kemunduran. Produk baru di sini dapat berupa produk yang baru secara fisik/fungsi atau produk baru dalam pandangan konsumen, bergantung pada struktur dari perusahaan. Titik yang dipilih seperti titik $\boldsymbol{A}$ dalam Gambar 1 dalam sistem yang ada menggambarkan keterlambatan untuk sebuah produk baru untuk memasuki pasar karena, titik ini adalah periode dimana perusahaan menahan pengeluaran biaya untuk usaha penjualan lainnya seperti promosi, diskon, dan lain-lain, untuk tetap menjaga agar penjualan tetap aktif.

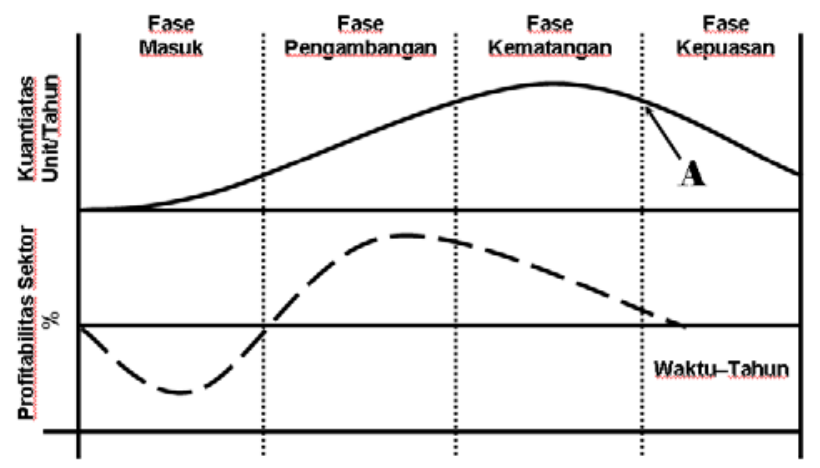

Gambar 1. Periode daur hidup dari sebuah produk

Untuk memudahkan manajemen membuat keputusan seperti di atas maka diperlukan sebuah sistem pakar fuzzy yang mampu untuk menjawab permasalahan di atas.

\section{METODE PENELITIAN}

Dalam membangun sistem pakar fuzzy, langkah yang penting adalah fuzzyfikasi dan membangun blok aturan fuzzy. Langkah ini dapat ditangani dengan 2 cara yang berbeda. Cara yang pertama adalah melalui wawancara dengan para pakar dari masalah yang dimaksud (knowledge-based reasoning). Sementara cara yang kedua adalah dengan menggunakan metode pembelajaran mesin (machine-learning), jaringan syaraf tiruan, dan algoritma genetika untuk mempelajari fungsi keanggotaan dan aturan fuzzy (case-based reasoning). Kedua pendekatan 
ini berbeda. Pendekatan pertama tidak membutuhkan sejarah dari masalah melainkan menurut pengalaman dari para pakar yang pernah bekerja dalam masalah ini selama bertahun-tahun. Pendekatan yang kedua berbasis hanya pada data-data yang pernah ada dan diproyeksikan ke depan dengan struktur yang sama. Dalam penyelesaian masalah ini kami mempergunakan pendekatan yang pertama.

Beberapa hal penting yang perlu diperhatikan dalam perancangan sistem pakar fuzzy adalah kelengkapan dari logika fuzzy itu sendiri seperti: fungsi keanggotaan, sistem inferensi, dan metode defuzzifikasi.

Fungsi keanggotaan (membership function) adalah suatu kurva yang menunjukkan pemetaan titik-titik data masukan ke dalam nilai keanggotaannya (sering juga disebut dengan derajat keanggotaan) yang memiliki interval antara 0 sampai dengan 1. Salah satu cara yang dapat digunakan untuk mendapatkan nilai keanggotaan adalah dengan pendekatan fungsi.

\section{Deskripsi Umum Sistem}

Perangkat lunak ini dapat dijalankan oleh server pada lingkungan sistem operasi Microsoft ${ }^{\circledR}$ Windows ${ }^{1}$ 95/98/NT/2000/XP dan dilengkapi web server Microsoft ${ }^{\circledR}$ Personal Web Server (PWS)/Microsoft ${ }^{\circledR}$ Internet Information Server (IIS) atau Apache Web Server yang mendukung bahasa pemrograman PHP: Hypertext Preprocessor (PHP) dan Matlab serta dibangun dengan menggunakan bahasa pemrograman PHP: Hypertext Preprocessor(PHP) dan Matlab.

\section{Lingkup Operasi}

Perangkat lunak pada sisi server yang dibutuhkan oleh

Sistem Pakar Fuzzy untuk Manajemen Daur Hidup Produk (SI SARY MAU UDUK) adalah:

- $\quad$ Sistem operasi : Microsof $₫$ Windows 95/98/NT/2000/XP

- Web server: Microsoft ${ }^{\circledR}$ Personal Web Server (PWS), Microsoft ${ }^{\circledR}$ Internet Information Server (IIS), Apache Web Server

- Scripting language: PHP: Hypertext Preprocessor (PHP)

- Engine: Matlab

Perangkat lunak pada sisi client yang dibutuhkan oleh SI SARY MAU UDUK adalah:

- Sistem operasi: Microsoft ${ }^{\circledR} \quad$ Windows 95/98/NT/2000/XP, Linux ${ }^{2}{ }^{2}$, UNIX ${ }^{\circledR}{ }^{3}$, MacOS, BeOS

- Penjelajah situs (web browser) berbasis grafis atau teks: Microsoft ${ }^{\circledR}$ Internet Explorer, Netscape ${ }^{\circledR}{ }^{4}$ Navigator, Opera, Modzilla, Konqueror, Nautilus, Lynx

\footnotetext{
${ }^{1}$ Microsoft ${ }^{\circledR}$ Windows adalah merk dagang terdaftar dari Microsoft Corp.

${ }^{2}$ Linux ${ }^{\circledR}$ adalah merk terdaftar dari Linus Torvalds

${ }^{3}$ UNIX ${ }^{\circledR}$ adalah merk dagang terdaftar dari Novell

${ }^{4}$ Netscape ${ }^{\circledR}$ adalah merk dagang terdaftar dari Netscape

Communications Corporation
}

Perangkat lunak ini dapat diakses oleh client pada lingkungan sistem operasi apapun yang mempunyai aplikasi penjelajah situs (web browser).

Gambar hubungan antar subsistem pada SI SARY MAU UDUK adalah sebagai berikut:

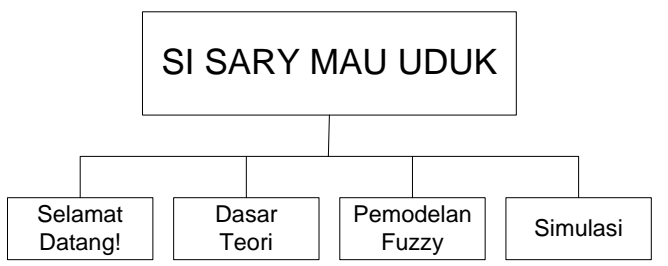

Gambar 2. Hubungan antar subsistem pada SI SARY MAU UDUK

\section{HASIL DAN PEMBAHASAN}

\section{Perancangan Sistem Pakar Fuzzy}

Berdasarkan identifikasi permasalahan di atas, maka dapat ditentukan variabel-variabel yang akan diketegorikan dalam variabel input dan variabel output, dimana variabel input dan output secara keseluruhan merupakan variabel linguistik.

\section{Variabel Input}

Menurut Hasiloglu et. al., variabel input dari masalah manajemen daur hidup produk dapat dibagi dalam 2 lapisan input. Variabel input pada lapisan yang pertama adalah: Kondisi Ekonomi, Keadaan Politik, Kompetisi, Usaha Pemasaran Lain, Peningkatan Penjualan Proporsional, Manufaktur, Renewal

Output dari lapisan input yang pertama adalah merupakan input dari lapisan yang kedua, dimana lapisan yang kedua berisi variabel input: Pasar Global, Manufaktur, Target Pasar, Variabel Output

Variabel output adalah nilai yang diharapkan dihasilkan dari sistem inferensi fuzzy. Sesuai dengan tujuan permasalahan diatas, maka variabel output adalah untuk menentukan performansi dari sebuah produk. Secara grafis, maka alur inferensi sistem fuzzy dari variabel input menuju variabel output dapat dilihat pada gambar di bawah ini:

\section{Atribut Linguistik dan Fungsi Keanggotaan Variabel Input:}

\section{A. Kondisi Ekonomi}

Atribut lingusistik dari variabel Kondisi Ekonomi adalah: Negatif, Tidak Efektif dan Positif. Sementara untuk merepresentasikan variabel Kondisi Ekonomi, digunakan kurva berbentuk bahu (untuk himpunan fuzzy Negatif dan Positif), dan kurva berbentuk segitiga (untuk himpunan fuzzy Tidak Efektif) dengan fungsi keanggotaan:

Fungsi keanggotaan:

$$
\mu_{\text {KondEk_Negatif }}[x]=\left\{\begin{array}{cc}
1 ; & x \leq 2 \\
(4.5-x) / 2.5 ; & 2 \leq x \leq 4.5 \\
0 ; & x \geq 4.5
\end{array}\right.
$$


$\mu_{\text {KondEk_TdkEfektif }}[x]=\left\{\begin{array}{cc}0 ; & x \leq 3.5, x \geq 6.5 \\ (x-3.5) / 1.5 ; & 3.5 \leq x \leq 5 \\ (5-x) / 1.5 ; & 5 \leq x \leq 6.5\end{array}\right.$

$\mu_{\text {KondEk_Positif }}[x]=\left\{\begin{array}{cc}0 ; & x \leq 5.5 \\ (x-5.5) / 2.5 ; & 5.5 \leq x \leq 8 \\ 1 ; & x \geq 8\end{array}\right.$

\section{B. Keadaan Politik}

Secara general variabel Keadaan Politik mempunyai penilaian yang sama dengan variabel Kondisi Ekonomi. Oleh sebab itu atribut lingusistik dan kurva yang digunakan untuk merepresentasikan variabel Keadaan Politik juga sama dengan variabel Kondisi Ekonomi.

Fungsi Keanggotaan:

$\mu_{\text {KeadnPol_Negatif }}[x]=\left\{\begin{array}{cc}1 ; & x \leq 2 \\ (4.5-x) / 2.5 ; & 2 \leq x \leq 4.5 \\ 0 ; & x \geq 4.5\end{array}\right.$

$\mu_{\text {KeadnPol_TdkEfektif }}[x]=\left\{\begin{array}{cc}0 ; & x \leq 3.5, x \geq 6.5 \\ (x-3.5) / 1.5 ; & 3.5 \leq x \leq 5 \\ (5-x) / 1.5 ; & 5 \leq x \leq 6.5\end{array}\right.$

$\left.\mu_{\text {KeadnPol_Positif }} x\right]=\left\{\begin{array}{cc}0 ; & x \leq 5.5 \\ (x-5.5) / 2.5 ; & 5.5 \leq x \leq 8 \\ 1 ; & x \geq 8\end{array}\right.$

\section{Kompetisi}

Atribut linguistik dari variabel Kompetisi: Meningkat dan Menurun. Sementara untuk merepresentasikan variabel Kompetisi, digunakan kurva linier dengan fungsi keanggotaan seperti terlihat bawah ini.

Fungsi keanggotaan:

$\mu_{\text {Komp_Menurun }}[x]=(7-x) / 7 ; x \leq 7$

$\mu_{\text {Komp_Meningkat }}[x]=(x-3) / 7 ; x \geq 3$

\section{Usaha Pemasaran Lain}

Atribut linguistik dari variabel Usaha Pemasaran Lain: Meningkat dan Menurun. Sementara untuk merepresentasikan variabel Usaha Pemasaran Lain, digunakan kurva linier naik untuk variabel Meningkat, dan kurva linier turun untuk variabel Menurun.

Fungsi Keanggotaan:

$\mu_{U P L}$ Menurun $[x]=(6-x) / 6 ; x \leq 6$

MUPL_Meningkat $[x]=(x-4) / 6 ; x \geq 4$

\section{E. Peningkatan Penjualan}

Atribut linguistik dari variabel Peningkatan Penjualan: Meningkat dan Menurun. Seperti variabel Kompetisi dan Usaha Pemasaran Lain, untuk merepresentasikan variabel Peningkatan Penjualan, digunakan representasi linier.

\section{Fungsi Keanggotaan:}

$\mu_{\text {PPenj_Menurun }}[x]=(6.5-x) / 6.5 ; x \leq 6$

$\mu_{P P e n j \_M e n i n g k a t}[x]=(x-3.5) / 6.5 ; x \geq 3.5$

\section{F. Manufaktur}

Atribut linguistik dari variable Manufaktur: Jelek, Bagus dan Sangat Bagus. Representasi grafis dari variabel Manufaktur, adalah kurva trapesium.

Fungsi keanggotaan:

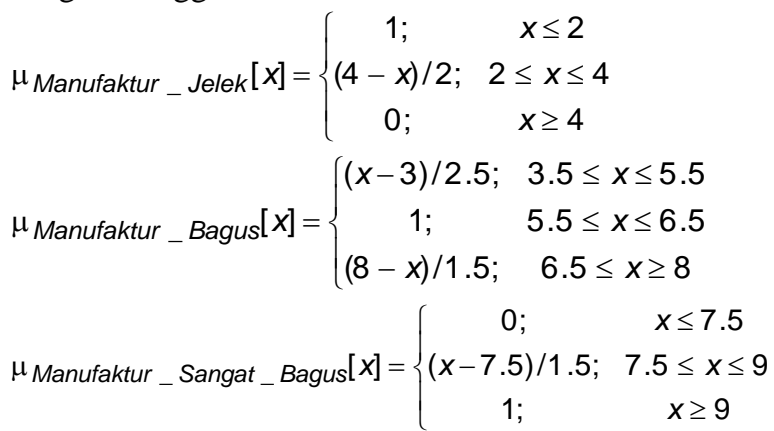

G. Renewal

Atribut linguistik dari variabel Renewal adalah: OK dan Tidak OK. Representasi variabel Renewal dalam kurva adalah seperti gambar di bawah ini.

Fungsi keanggotaan:

$$
\begin{aligned}
& \mu_{\text {Renewal_OK }}[x]=\left\{\begin{array}{cc}
(x-3) / 4.5 ; & 3 \leq x \leq 7.5 \\
1 ; & x \geq 7.5
\end{array}\right. \\
& \mu_{\text {Renewal_Tidak_OK }}[x]=1-\mu_{\text {Renewal_OK }}[x] \\
& =\left\{\begin{array}{cc}
(7.5-x) / 4.5 ; & 3 \leq x \leq 7.5 \\
0 ; & x \leq 3
\end{array}\right.
\end{aligned}
$$

Untuk lapisan input kedua yang terdiri dari Pasar Global, Manufaktur dan Renewal, atribut linguistik dan fungsi keanggotaannya adalah sebagai berikut:

\section{H. Pasar Global}

Atribut linguistik dari variabel Pasar Global: Optimis dan Pesimis. Representasi variabel Pasar Global dan fungsi keanggotaannya diperlihatkan pada gambar berikut.

Fungsi keanggotaan:

$\mu_{\text {PGlobal_Pesimis }}[x]=(6-x) / 6 ; x \leq 6$

$\mu_{\text {PGlobal_Optimis }}[x]=(x-5) / 5 ; x \geq 5$

\section{Manufaktur}

Atribut linguistik dari variabel Manufaktur: Jelek, Bagus dan Sangat Bagus. Untuk merepresentasikan variabel Manufaktur, digunakan kurva berbentuk segitiga untuk variabel Bagus dan kurva trapesium untuk variabel Jelek dan Sangat Bagus.

Fungsi keanggotaan:

$$
\begin{gathered}
\mu_{\text {Manufaktur_Jelek }}[x]=\left\{\begin{array}{cc}
1 ; & x \leq 2.5 \\
(5-x) / 2.5 ; & 2.5 \leq x \leq 5 \\
0 ; & x \geq 5
\end{array}\right. \\
\mu_{\text {Manufaktur_Bagus }}[x]=\left\{\begin{array}{cc}
0 ; & x \leq 4 ; x \geq 8 \\
(x-4) / 2 ; & 4 \leq x \leq 6 \\
(8-x) / 2 ; & 6 \leq x \geq 8
\end{array}\right.
\end{gathered}
$$




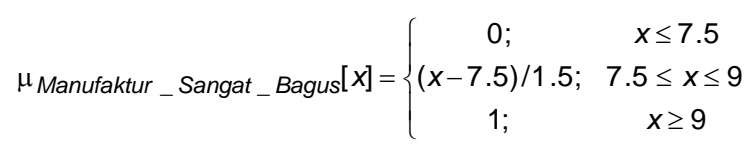

\section{J. Target Pasar}

Atribut linguistik dari variabel Target Pasar: Tunggu, Medium dan Impulsif. Untuk merepresentasikan variabel Target Pasar, digunakan kurva berbentuk trapesium untuk variabel Tunggu dan Impulsif, sementara untuk variabel Medium dipakai kurva segitiga.

Fungsi keanggotaan:

$\mu_{\text {TgtPasar_Tungu }}[x]=\left\{\begin{array}{cc}1 ; & x \leq 1 \\ (4-x) / 3 ; & 1 \leq x \leq 4 \\ 0 ; & x \geq 4\end{array}\right.$

$\mu_{\text {TgtPasar_Medium }}[x]=\left\{\begin{array}{cc}0 ; & x \leq 3 ; x \geq 7 \\ (x-3) / 2 ; & 3 \leq x \leq 5 \\ (7-x) / 2 ; & 5 \leq x \leq 7\end{array}\right.$

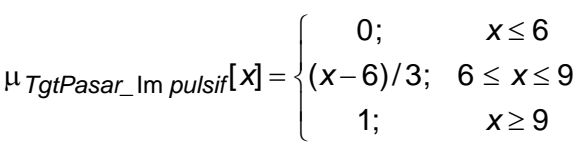

\section{Atribut Linguistik dan Fungsi Keanggotaan Variabe Output}

Variabel output didefinisikan sebagai Performansi, yang menandakan keberadaan dari produk di pasaran. Oleh sebab itu variabel linguistik dari Performansi adalah Aktif, Pasif dan Jelek. Representasi kurva dan fungsi keanggotaannya adalah sebagai berikut:

Fungsi keanggotaan:

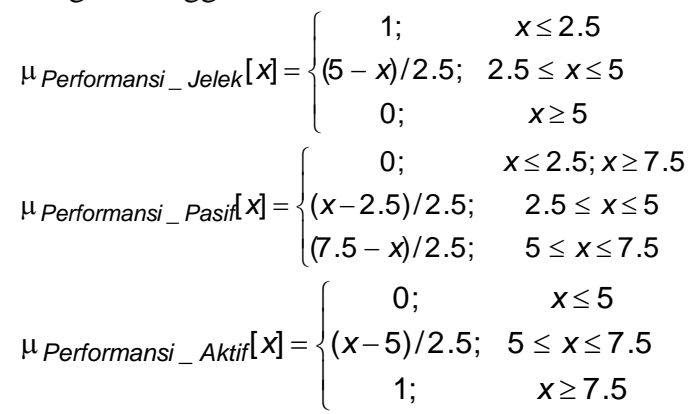

Definisi Blok Aturan:

Blok Aturan Lapisan Input 1

Blok aturan (IF-THEN rules block) lapisan input pertama adalah aturan dengan input lapisan pertama dan outputnya adalah input pada lapisan kedua. Selengkapnya terdapat pada tabel-tabel di bawah ini:

Tabel 1. Blok aturan Pasar Global

\begin{tabular}{|c|c|c|c|}
\hline \multicolumn{3}{|c|}{ JIKA } & \multirow{2}{*}{$\begin{array}{c}\text { MAKA } \\
\text { Pasar } \\
\text { Global }\end{array}$} \\
\hline $\begin{array}{l}\text { Kondisi } \\
\text { Ekonomi }\end{array}$ & \& & Keadaan Politik & \\
\hline Negatif & & Negatif & Pesimis \\
\hline Negatif & & Tidak Efektif & Pesimis \\
\hline Negatif & & Positif & Pesimis \\
\hline Tidak Efektif & & Negatif & Pesimis \\
\hline Tidak Efektif & & Tidak Efektif & Pesimis \\
\hline
\end{tabular}

\begin{tabular}{lll} 
Tidak Efektif & Positif & Optimis \\
Positif & Negatif & Pesimis \\
Positif & Tidak Efektif & Optimis \\
Positif & Positif & Optimis \\
\hline
\end{tabular}

Dalam blok aturan Target Pasar, Titik Manufaktur adalah perbandingan performansi dari produk dengan produk perusahaan saingan. Performansi dari produk bisa lebih rendah, sama, atau lebih tinggi dari produk perusahaan saingan. $M p$ pada tabel di atas adalah titik manufaktur dari perusahaan, sementara $\mathrm{cmp}$ adalah titik manufaktur dari perusahaan saingan.

Tabel 2. Blok aturan Manufaktur

\begin{tabular}{lllll}
\hline & JIKA & \multicolumn{1}{c}{ MAKA } \\
\hline Kompetisi & $\&$ & $\begin{array}{c}\text { Usaha } \\
\text { Pmsrn. }\end{array}$ & $\begin{array}{c}\text { Pening. } \\
\text { Penj. }\end{array}$ & Manufaktur \\
\hline Menurun & Menurun & Menurun & Jelek \\
Menurun & Menurun & Meningkat & Bagus \\
Menurun & Meningkat & Menurun & Bagus \\
Menurun & Meningkat & Meningkat & Sangat Bagus \\
Meningkat & Menurun & Menurun & Bagus \\
Meningkat & Menurun & Meningkat & Sangat Bagus \\
Meningkat & Meningkat & Menurun & Sangat Bagus \\
Meningkat & Meningkat & Meningkat & Sangat Bagus \\
\hline
\end{tabular}

Tabel 3. Blok aturan Target Pasar

\begin{tabular}{|c|c|c|c|}
\hline \multicolumn{3}{|c|}{ JIKA } & \multirow{2}{*}{$\begin{array}{c}\text { MAKA } \\
\text { Target Pasar }\end{array}$} \\
\hline $\begin{array}{c}\text { Titik } \\
\text { Manufaktur }\end{array}$ & \& & Renewal & \\
\hline $\mathrm{Mp}<\mathrm{cmp}$ & & Tidak OK & Tunggu \\
\hline $\mathrm{Mp}<\mathrm{cmp}$ & & $\mathrm{OK}$ & Medium \\
\hline $\mathrm{Mp}=\mathrm{cmp}$ & & Tidak OK & Tunggu \\
\hline $\mathrm{Mp}=\mathrm{cmp}$ & & $\mathrm{OK}$ & Impulsif \\
\hline $\mathrm{Mp}>\mathrm{cmp}$ & & Tidak OK & Medium \\
\hline $\mathrm{Mp}>\mathrm{cmp}$ & & $\mathrm{OK}$ & Impulsif \\
\hline
\end{tabular}

\section{Blok Aturan Lapisan Input 2}

Dalam blok aturan lapisan kedua, yang bertindak sebagai input adalah output dari lapisan input pertama dan sebagai outputnya adalah variabel output performansi.

Tabel 4. Blok aturan Performansi Produk

\begin{tabular}{|c|c|c|c|c|c|}
\hline \multicolumn{5}{|c|}{ JIKA } & MAKA \\
\hline $\begin{array}{l}\text { Pasar } \\
\text { Global }\end{array}$ & \& & Manufaktur & \& & $\begin{array}{l}\text { Target } \\
\text { Pasar }\end{array}$ & Performansi \\
\hline Pesimis & & Jelek & & Tunggu & Jelek \\
\hline Pesimis & & Jelek & & Medium & Jelek \\
\hline Pesimis & & Jelek & & Impulsif & Pasif \\
\hline Pesimis & & Bagus & & Tunggu & Jelek \\
\hline Pesimis & & Bagus & & Medium & Pasif \\
\hline Pesimis & & Bagus & & Impulsif & Pasif \\
\hline Pesimis & & Sangat Bagus & & Tunggu & Pasif \\
\hline Pesimis & & Sangat Bagus & & Medium & Pasif \\
\hline Pesimis & & Sangat Bagus & & Impulsif & Aktif \\
\hline Optimis & & Jelek & & Tunggu & Pasif \\
\hline
\end{tabular}




\begin{tabular}{lccc} 
Optimis & Jelek & Medium & Pasif \\
Optimis & Jelek & Impulsif & Aktif \\
Optimis & Bagus & Tunggu & Pasif \\
Optimis & Bagus & Medium & Aktif \\
Optimis & Bagus & Impulsif & Aktif \\
Optimis & Sangat Bagus & Tunggu & Aktif \\
Optimis & Sangat Bagus & Medium & Aktif \\
Optimis & Sangat Bagus & Impulsif & Aktif \\
\hline
\end{tabular}

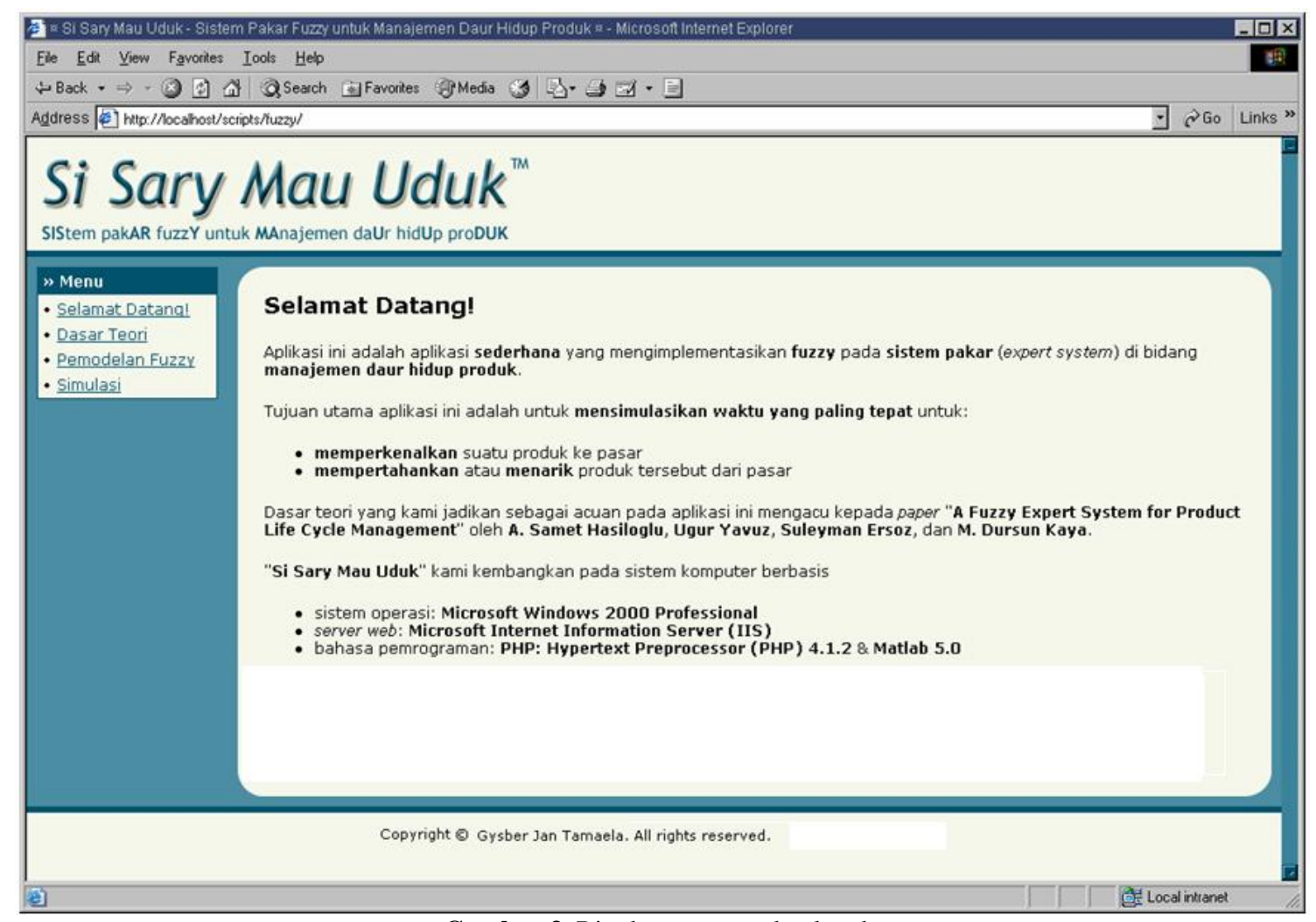

Gambar 3. Ringkasan perangkat lunak. 


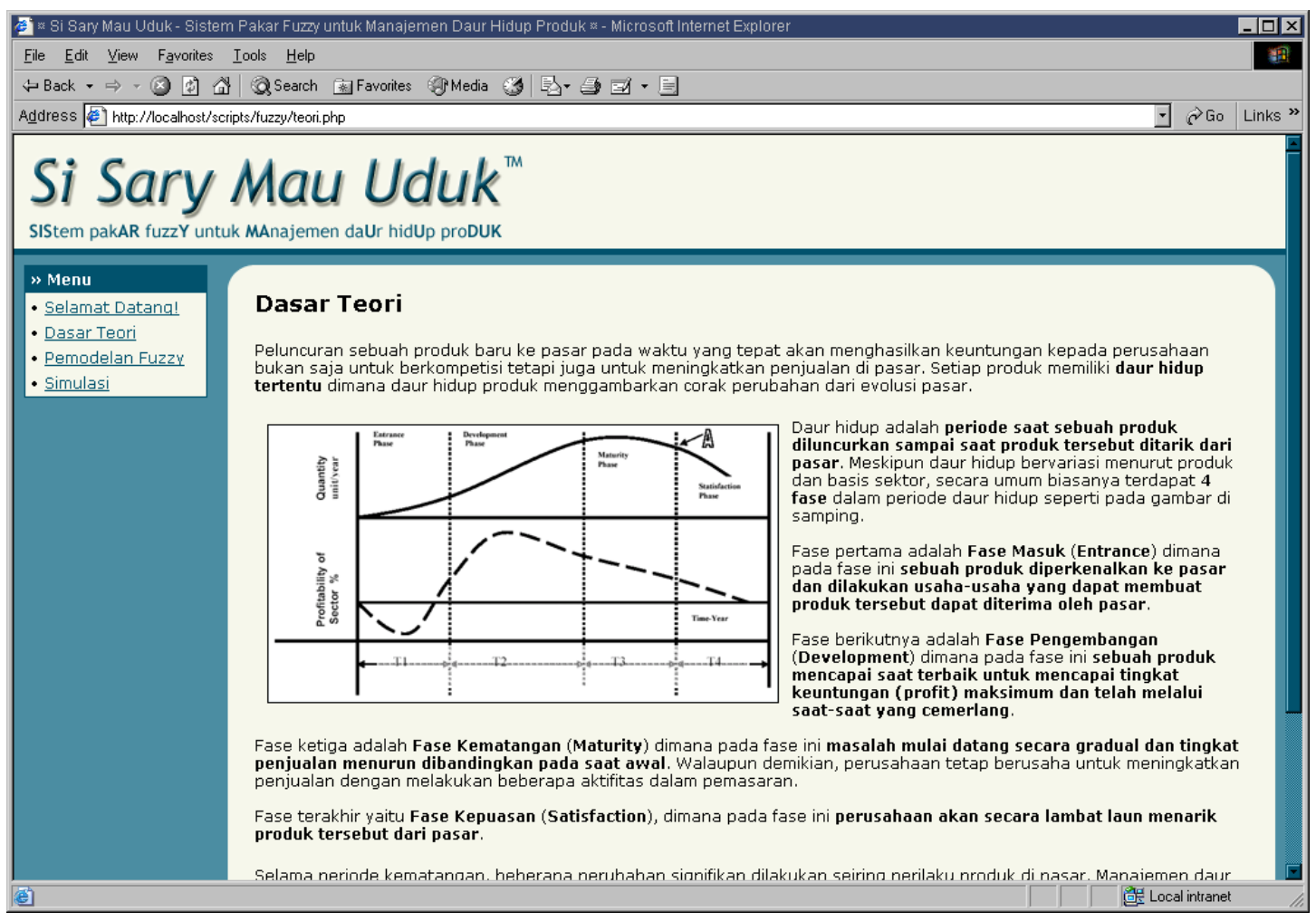

Gambar 4. Dasar teori daur hidup suatu produk

Pada Gambar 3 menampilkan ringkasan dari perangkat lunak ini. Ringkasan yang dimaksud mencakup tujuan utama, sumber dari dasar teori, spesifikasi perangkat keras yang digunakan dalam pengembangan perangkat lunak, dan pengembang perangkat lunak. Sementara Gambar 4 menampilkan informasi mengenai dasar teori manajemen daur hidup produk yang diimplementasikan pada perangkat lunak ini. Informasi pemodelan fuzzy yang digunakan untuk manajemen daur hidup produk yang diimplementasikan pada perangkat lunak ini ditampilkan pada Gambar 5.

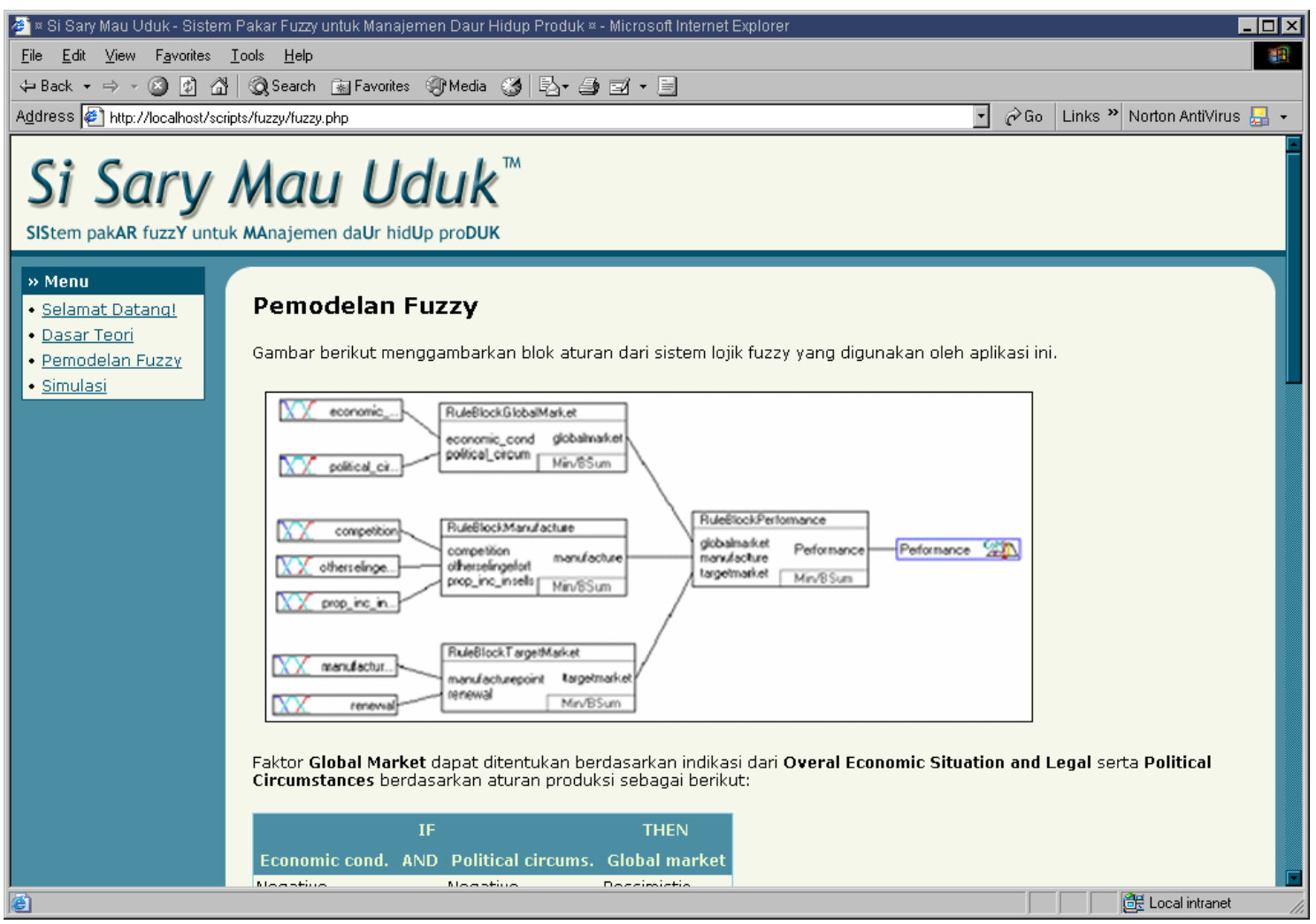


Gambar 5. Pemodelan fuzzy yang digunakan pada pemodelan daur hidup produk.

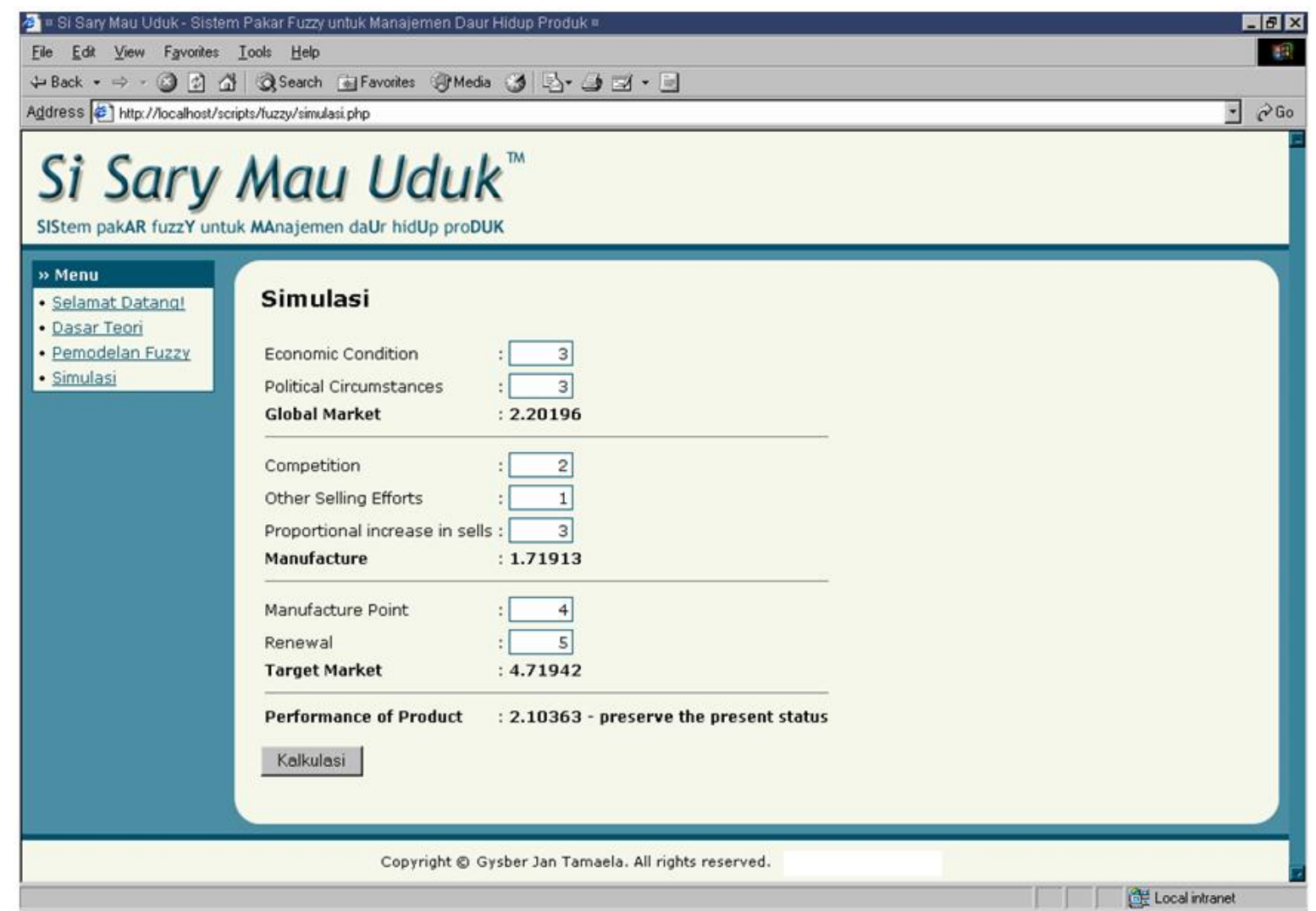

Gambar 6. Simulasi daur hidup produk berdasarkan sejumlah kriteria.

Gambar 6 menampilkan simulasi manajemen daur hidup produk berdasarkan data masukan yang terdapat pada dasar teori dan pemodelan fuzzy. Di sini nilai input yang dicoba adalah Economic Condition $=3$, Political Circumstances $=3$, Competition $=2$, Other Selling Efforts $=1$, Propotional increase in sells $=3$, Manufacture Point $=4$ dan Renewal $=5$. Output lapisan pertama adalah: Global Market $=$ 2,20196, Manufacture $=1,71913$ dan Target Market $=4,71942$. Hasil akhir dari perangkat lunak ini adalah Performance of Product dengan nilai 2.10363, yang atribut linguistiknya adalah "preserve the present status".

\section{KESIMPULAN}

Dengan adanya pernangkat lunak SI SARY MAU UDUK ini dapat mempermudah manajemen untuk mengambil keputusan tentang masa daur hidup sebuah produk

\section{DAFTAR PUSTAKA}

Bayu Hendradjaya. Panduan Penulisan Spesifikasi Kebutuhan Perangkat Lunak (SKPL). Jurusan Teknik Informatika ITB.

Danny Goodman and Brendan Eich. JavaScript Bible. Hungry Minds, Inc. Maret 1998.

[DAV99] Dave Raggett, Arnaud Le Hors, dan Ian Jacobs. HTML 4.01 Specification. W3C Recommendation. Desember 1999.

Stig Sæther Bakken and Egon Schmid. PHP Manual. PHP Documentation Group. 2001.
Netscape Communications Corporation. Client-Side Javascript Reference. Netscape Communications Corporation. November 1998.

STAF IF. GL01, Spesifikasi Kebutuhan Perangkat Lunak. Jurusan Teknik Informatika ITB.

Marimin, Dr., Ir., M.Sc., Teori dan Aplikasi Sistem Pakar dalam Teknologi Manajerial. IPB Press. 2002.

Samet Hasiloglu, Ugur Yavus, Suleyman Ersoz, M. Dursun Kaya. A Fuzzy Expert System for Product Life Cycle Management. International XII. Turkish Symposium on Artificial Intelligence and Neural Networks - TAINN. 2003.

Kusumadewi, Sri, S.Si., MT, Artificial Intelligence (Teknik dan Aplikasinya). Graha Ilmu. 2003.

Kusumadewi, Sri, S.Si., MT, Analisis dan Desain Sistem Fuzzy - Menggunakan Toolbox MATLAB. Graha Ilmu. 2002.

Komninos, Ioannis, B.Eng., M.Sc., Product Life Cycle Management, www.urenio.org

Wikipedia-The Free Encyclopedia, www.wikipedia.com. 